\title{
Effect of Well Completion, Slug Size and WAP Timing on the Performance of Polymer Flooding
}

\author{
Gamal Alusta $^{1 *}$, Rana Saqer ${ }^{2}$ and Hadel Mohsen ${ }^{1}$ \\ ${ }^{\prime}$ Department of Petroleum Engineering and Chemical Engineering, United Arab Emirates University, Al Ain, United Arab Emirates \\ ${ }^{2}$ Teaching Assistant, Department of Petroleum Engineering, Abu Dhabi Polytechnic, United Arab Emirates
}

\section{Article Info}

*Corresponding author:
Gamal Alusta
Assistant Professor
Department of Petroleum Engineering and
Chemical Engineering
United Arab Emirates University
Al Ain, United Arab Emirates
E-mail: gamal.alusta@uaeu.ac.ae

Received: March 6, 2019

Accepted: March 25, 2019

Published: April 1, 2019

Citation: Alusta G, Saqer R, Mohsen H. Effect of Well Completion, Slug Size and WAP Timing on the Performance of Polymer Flooding. Int J Petrochem Res. 2019; 3(1): 280-285.

doi: 10.18689/ijpr-1000148

Copyright: (c) 2019 The Author(s). This work is licensed under a Creative Commons Attribution 4.0 International License, which permits unrestricted use, distribution, and reproduction in any medium, provided the original work is properly cited.

Published by Madridge Publishers

\begin{abstract}
The objective of this work is to asses and select the development options using polymer process that maximize oil recovery for a synthetic reservoir model where technical parameters are optimized thoroughly. Reservoir simulation study using ECLIPSE 100 was used to simulate the synthetic model to investigate the different development options of polymer flooding applied and compare them to water flooding. The development options include continuous polymer injection, water alternating polymer, and polymer slug injection. Through the study, the effect of injection rate, polymer concentration, slug size, and well completion were investigated by setting up a range of sensitivities.
\end{abstract}

Keywords: Slug Size; Oil recovery; Injection rate; Polymer concentration.

Abbreviations: FOE: Field Oil Efficiency (\%); FOPR: Field Oil Production Rate (STB/D); FOPT: Field Oil Production Total (STB); FPR: Field Pressure (psia); FWCT: Field Water cut (dimensionless); FWIR: Field Water Injection Rate (STB/D); FWPT: Field Water Production Total (STB); WCIR: Field Polymer Injection Rate (LB/D); WCPT: Field Polymer Production Total (LB).

\section{Introduction}

The life of an oil reservoir goes through three distinct phases namely primary, secondary, and tertiary or enhanced oil recovery. The importance of EOR techniques is to improve the displacement efficiency by reducing the residual oil saturation that results in high ultimate oil recovery [1].

Polymer flooding is one of the mostly used chemical EOR methods. It uses polymer solutions to increase the viscosity of the displacing fluid and/or reduce the effective permeability of rock to the injected fluid and thus lower the displacing fluid (water)/oil mobility ratio leading to an increase in oil recovery. After normal water flooding, polymers maybe injected for one to two years to effectively reach the residual oil saturation; since polymer flooding does not affect the end point $\mathrm{S}_{\mathrm{or}}$ a reduction in the effective $S_{\text {or }}$ is achieved at the economic limit. This reduction is dependent on the nature of the fractional flow curve and the volume of injected water [2].

Exponential increase of polymer flooding projects has been due to the affordable price of polymers compared to oil; where the mostly used polymers by the industry are hydrolyzed polyacrylamides (HPAM) and biopolymer xanthan [2,3].

The primary mechanism of a polymer flood is to increase the volumetric sweep efficiency by means of mobility control. Furthermore, the implementation of polymer process reduces fingering effect which is a main problem in water flooding application. By doing so, the volumetric sweep efficiency increases [4]. 
In this paper, engineering design aspects of polymer flooding were analyzed and identified to assess full field development options for polymer injection that will achieve ultimate recovery.

\section{Development Options Identification}

The assessment and selection of the development option that will maximize the oil recovery needs to be defined through viable development options and processes.

In defining the constraints, all dependent variables that will affect the results of the study will be considered [5].

In this study, two development processes were identified: water flooding and polymer flooding.

For the polymer flooding process, the following development injection plans will be identified for analysis:

- Continuous polymer injection

- Water alternating polymer (WAP) injection

- Polymer slug injection

Through the study the effect of injection rate, polymer concentration, polymer timing and well completion were studied.

- Injection rate $(200,500,1000,1500,2000,2500,3000$, and 3500 STB/D)

- Polymer concentration (200, 500, 1000, 1500, and 2000 ppm)

- Polymer timing

- WAP time cycle of $1,3,6$, and 12 months, where the WAP ratio is 1:1.

- Polymer slug injection: 2, 3, and 5 years of polymer injection after two years of water flooding, and then the injection proceed with water.

- Well completion (COMP1, COMP2, COMP3, COMP4, and (OMP5) where, each completion is defined in table 1 and illustrated in figure 1.

Table 1. Well completion intervals.

\begin{tabular}{|l|c|c|}
\hline \multicolumn{1}{|c|}{ Well Completion } & Injector & Producer \\
\hline COMP1 & All layers & All layers \\
\hline COMP2 & Layers 2 \& 3 & Layers 1 \& 2 \\
\hline COMP3 & Layers 1 \& 3 & Layers 1 \& 3 \\
\hline COMP4 & Layers 1 \& 3 & Layer 2 \\
\hline COMP5 & Layer 2 & Layer 2 \\
\hline
\end{tabular}

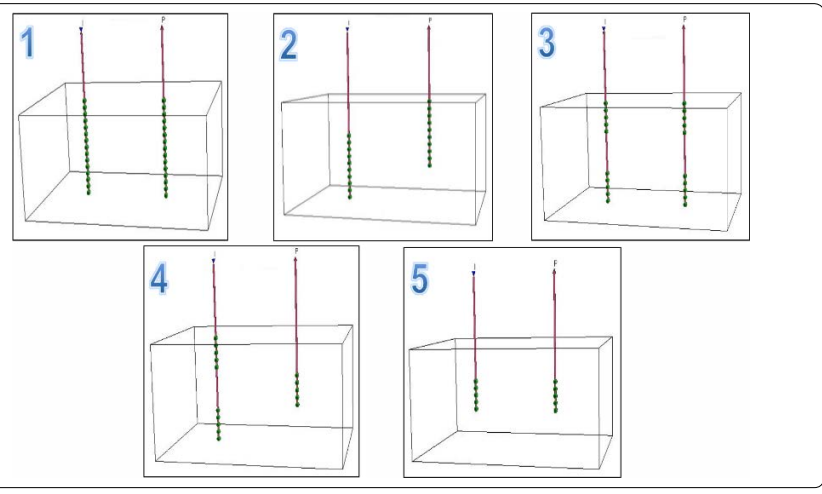

Figure 1. Well completion intervals.
A total of 133 simulation runs were prepared and run using the ECLIPSE 100 simulator. Figure 2 is a flow chart representing the development processes of polymer flooding throughout the study, where the output from the water flooding sensitivity analysis will be fed as an input in terms of optimum injection rate and best completion practices.

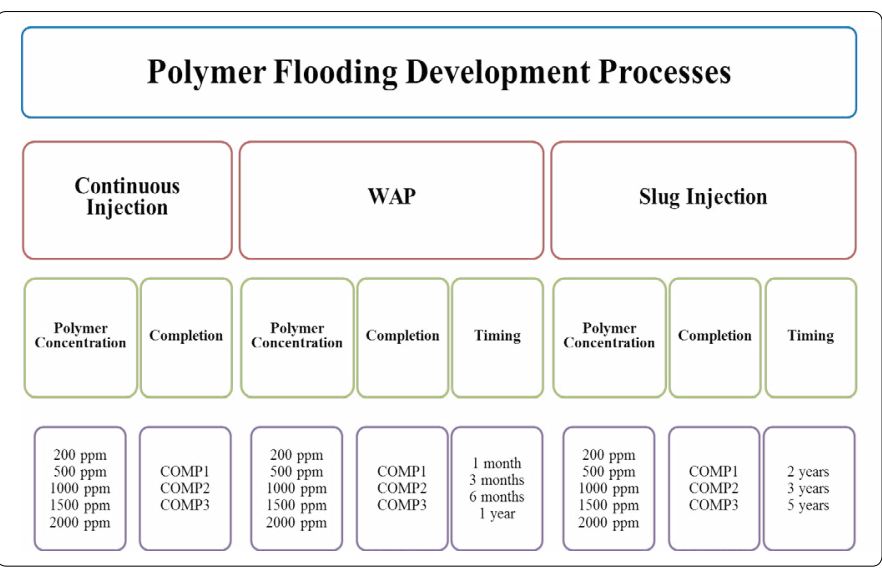

Figure 2. Polymer flooding development options.

\section{Development Process Assess Study}

\section{Water flooding process}

For the water flooding process, the prediction runs were simulated by studying the effect of injection rate and well completion.

Injection rate sensitivity analysis: The base case completion (COMP1) was set for all runs to study the effect of various injection rates on the performance of the water flood where 2000 STB/D is the base case injection rate.

The results of the five simulation runs are shown in table 2 .

Table 2. Waterflooding injection results using COMP1.

\begin{tabular}{|l|c|c|c|c|c|c|}
\hline $\begin{array}{l}\text { Injection } \\
\text { Rate (STB/D) }\end{array}$ & $\begin{array}{c}\text { FOPR } \\
\text { (STB/D) }\end{array}$ & $\begin{array}{c}\text { FOPT } \\
\text { (STB) }\end{array}$ & $\begin{array}{c}\text { FWPT } \\
\text { (STB) }\end{array}$ & $\begin{array}{c}\text { WCIR } \\
\text { (LB/D) }\end{array}$ & $\begin{array}{c}\text { WCPT } \\
\text { (LB) }\end{array}$ & $\begin{array}{c}\text { FOE } \\
\text { (\%) }\end{array}$ \\
\hline 200 & 126.87 & $2.40 \mathrm{E}+6$ & $0.34 \mathrm{E}+6$ & 0.0 & 0.0 & 18.02 \\
\hline 500 & 163.36 & $3.97 \mathrm{E}+6$ & $3.03 \mathrm{E}+6$ & 0.0 & 0.0 & 29.78 \\
\hline 1000 & 173.05 & $5.40 \mathrm{E}+6$ & $8.88 \mathrm{E}+6$ & 0.0 & 0.0 & 40.43 \\
\hline 1500 & 149.92 & $6.13 \mathrm{E}+6$ & $15.5 \mathrm{E}+6$ & 0.0 & 0.0 & 45.98 \\
\hline 2000 & 195.73 & $6.00 \mathrm{E}+6$ & $15.83 \mathrm{E}+6$ & 0.0 & 0.0 & 44.93 \\
\hline 2500 & 249.90 & $5.82 \mathrm{E}+6$ & $15.29 \mathrm{E}+6$ & 0.0 & 0.0 & 43.60 \\
\hline 3000 & 293.09 & $5.72 \mathrm{E}+6$ & $15.18 \mathrm{E}+6$ & 0.0 & 0.0 & 42.88 \\
\hline 3500 & 355.06 & $5.61 \mathrm{E}+6$ & $14.39 \mathrm{E}+6$ & 0.0 & 0.0 & 42.02 \\
\hline
\end{tabular}

Based on the illustrated results, the following can be deduced:

- A $30 \%$ water cut has been reached at 200 STB/D where the water started to breakthrough after 9 years of water injection.

- Water breakthrough was observed after 4 years at $500 \mathrm{STB} / \mathrm{D}, 2$ years at 1000 and 1500 STB/D, and 1 year at 2000 STB/D and higher injection rates.

- An improvement in FOE of about $10 \%$ is noticed at 1000 STB/D compared to 200 and 500 STB/D.

- After the drawdown period which lasted for a year, the pressure started to build up since the effect of water has been felt.

- Injecting 1500 STB/D gave the highest recovery at maximum water cut of $90 \%$. 
- Water cut of $90 \%$ has been reached earlier (10 years before) at injection rate of 2000 STB/D compared to other rates including 200,500, 1000 and 1500 STB/D. Therefore, oil producer was closed. However, $90 \%$ water cut has been reached further earlier using injection rates of 2500, 3000 and 3500 STB/D.

According to what has been found, the maximum oil recovery was achieved at an injection rate of 1500 STB/D, with $1.05 \%$ difference from the base case injection rate (2000 STB/D). Injection rate of 200 and 500 STB/D are considered to be too low and they delay the breakthrough with bad recovery compared to other injection rates. Fast breakthrough was observed at 2000 STB/D and at higher injection rates as shown in recovery profile at $90 \%$ water cut using different injection rate as in figure 3. Thus, 1500 STB/D was considered the most suitable operating injection rate for this study.

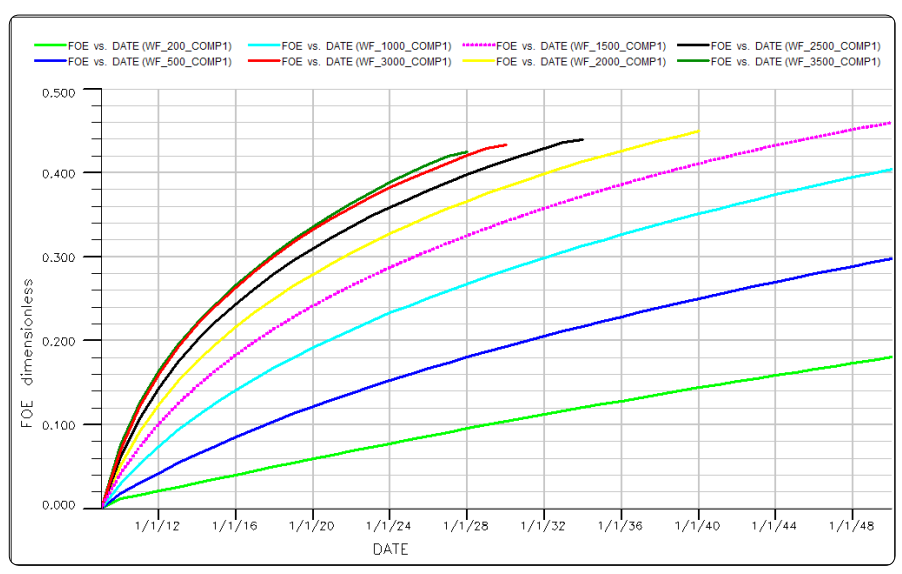

Figure 3. Oil recovery at $90 \%$ water cut for different injection rates, waterflooding process.

Well completion sensitivity analysis: The results of five completions attempted at an injection rate of 1500 STB/D are shown in table 3.

Table 3. Water flooding injection results at injection rate of 1500 STB/D.

\begin{tabular}{|l|c|c|c|c|c|c|}
\hline COMP & $\begin{array}{c}\text { FOPR } \\
\text { (STB/D) }\end{array}$ & $\begin{array}{c}\text { FOPT } \\
\text { (STB) }\end{array}$ & $\begin{array}{c}\text { FWPT } \\
\text { (STB) }\end{array}$ & $\begin{array}{c}\text { WCIR } \\
\text { (LB/D) }\end{array}$ & $\begin{array}{c}\text { WCPT } \\
\text { (LB) }\end{array}$ & $\begin{array}{c}\text { FOE } \\
(\%)\end{array}$ \\
\hline 1 & 149.92 & $6.13 \mathrm{E}+6$ & $15.5 \mathrm{E}+6$ & 0.0 & 0.0 & 45.98 \\
\hline 2 & 150.22 & $6.20 \mathrm{E}+6$ & $15.42 \mathrm{E}+6$ & 0.0 & 0.0 & 46.47 \\
\hline 3 & 153.83 & $6.12 \mathrm{E}+6$ & $14.46 \mathrm{E}+6$ & 0.0 & 0.0 & 45.85 \\
\hline 4 & 148.70 & $5.96 \mathrm{E}+6$ & $14.58 \mathrm{E}+6$ & 0.0 & 0.0 & 44.68 \\
\hline 5 & 150.56 & $5.92 \mathrm{E}+6$ & $15.74 \mathrm{E}+6$ & 0.0 & 0.0 & 44.34 \\
\hline
\end{tabular}

The main findings can be summarized as follows:

- The plateau period was 40 years when COMP1, COMP2, and COMP5 were used. Hence, using COMP4 it was 38 years.

- The water breakthrough took place after 1 year for COMP1, COMP2, COMP3, and COMP4; and after 2 years for COMP5.

- The reservoir pressure started to increase at water breakthrough.

- Oil producer was closed because it reached the maximum water cut of $90 \%$.

- The plateau of water injection rate was maintained for a short period of time due to the increase in reservoir pressure. Then, it built up again.
- Maximum oil recovery was achieved using COMP2, followed by COMP1, COMP3, and COMP4, and the least recovery was obtained using COMP5. An increment of $2.13 \%$ in FOE using COMP2 is obtained over COMP5 (Figure 4).

- It is preferable from the technical point not to perforate high permeable zone. In this case the oil in the lower permeability intervals will be bypassed.

Based on that, the first three completions will be used in the technical sensitivity analysis of different development options of polymer flooding.

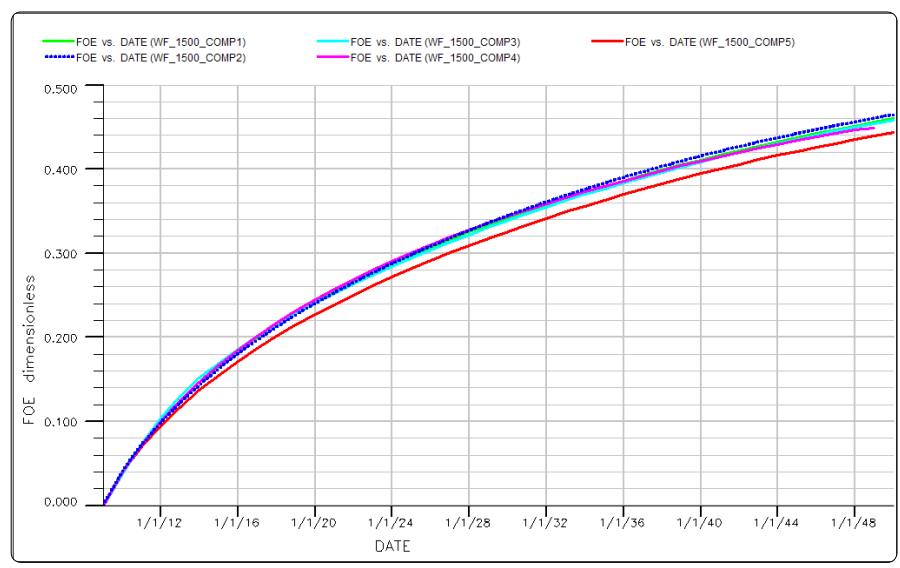

Figure 4. Oil recovery at $90 \%$ water cut for different well completions, water flooding process.

\section{Polymer flooding process}

Continuous polymer injection: A total of fifteen runs were simulated where figure 5 shows the oil recovery obtained for different polymer concentrations corresponding to the three completions attempted.

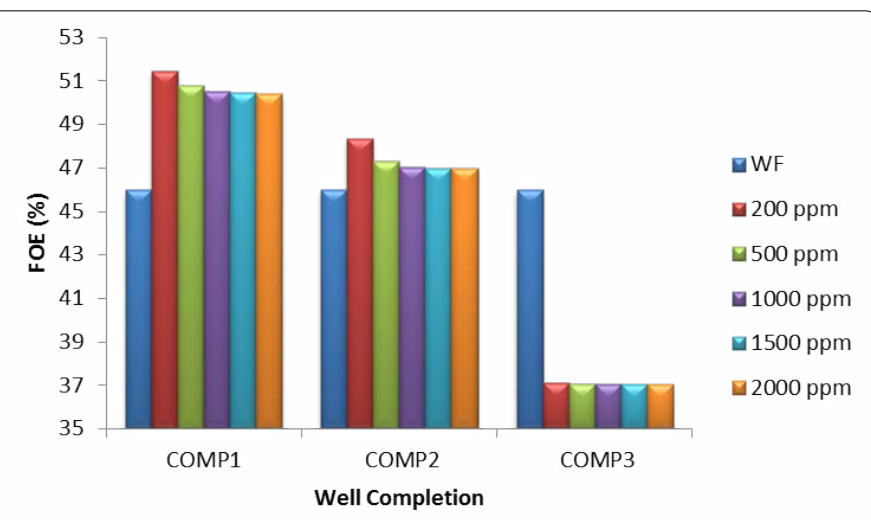

Figure 5. FOE vs. well completion at different polymer concentrations (continuous polymer injection).

A $5.45 \%$ increase in oil recovery is obtained over water flooding once polymer injection is applied at minimum concentration of 200 ppm using COMP1. On the other hand, completing the well using COMP3 reduces the oil recovery by $8.85 \%$ respectively over water flooding at minimum polymer concentration used. This can be justified due to perforating both the injector and producer in the two geological layers of low permeability, where the continuous injection of polymer solution in this case leads to pores blockage even at low concentrations of polymer. As a result, COMP3 will not be 
utilized as an option to improve oil recovery and completing the well at all layers for injection and production gave the highest recovery for all polymer concentrations attempted.

Furthermore, reducing the polymer concentration from $2000 \mathrm{ppm}$ to $200 \mathrm{ppm}$ improved the recovery by $1 \%$ using COMP1 and by $1.38 \%$ using COMP2. It is necessary in this case to choose and select the appropriate polymer concentration to be injected in order to minimize extra costs, since the effect of increasing polymer concentration beyond a certain value will not be sound. Based on theory, fingering can be avoided by continuous injection of polymer solution instead of water. This will improve the mobility of the injectant; thus, increases the oil recovery efficiency. But since the polymers are more expensive than water, this will limit the volume of injected polymer solution. In most cases, continuous injection of polymer is not economical.

Polymer injection could be resumed after 2050 since water cut economic limit of $90 \%$ has not been reached while for water injection it has been. At 2050, an average water cut is reached of about $65 \%, 55 \%$ and $35 \%$ using COMP1, COMP2, and COMP3 respectively.

Water alternating polymer (WAP) injection: Sixty simulation runs were performed to study the effect of implementing WAP injection; different WAP time cycles, polymer concentrations and well completions were examined.

From the simulation runs, similar results were observed during the WAP process for all WAP cycle time intervals attempted using COMP1. Increasing the polymer concentration from 200 to 2000 ppm has an adverse effect on the oil recovery; thus, an increment of $8.1 \%$ in oil recovery can be attained using 200 ppm when it has been injected as a slug of $0.00704 \mathrm{PV}$ alternating with the same pore volume of water.

The effect of injecting different pore volumes of water followed by the same pore volume of polymer solution (WAP ratio $1: 1$ ) including $0.00235,0.00704,0.014$, and 0.0285 where each denotes that both slugs (water and polymer solution) will last for one, three, six, and twelve months respectively, keeping both the polymer concentration and the selected completion constant is significant. A summary of the FOE results is illustrated in figure 6 . From the results presented, the following points can be deduced:

- Difference in FOE between 1500 ppm and 2000 ppm is very minor compared to other concentrations.

- When applying the same WAP cycle time period for the study, WAP injection gave higher FOE than continuous polymer injection using the same well completion (COMP1).

- Injecting 0.00235, 0.00704, and 0.014 PV improves the oil recovery over normal waterflooding; while the injection of 0.0285 PV of 1500 ppm and 2000 ppm polymer concentrations reduces the FOE.

- Increasing the injection slug time as a WAP process gave lower oil recovery; thus applying WAP injection at relatively small slugs is preferable in this case.

\section{Results and Discussion}

The overall results of the simulation runs attempted using COMP2 are presented in figure 6 . In this case, the minimum requirements in terms of polymer should be considered to increase the recovery over normal water flooding. The results reveal that in order to obtain higher recoveries when COMP2 is applied, the study period needs to be extended and this is applicable; since $90 \%$ economic limit of water cut has not been reached. Referring to the results obtained using COMP1, higher oil recoveries are achieved over COMP2 for the same WAP cycle intervals; keeping the reservoir pressure maintained throughout the study.

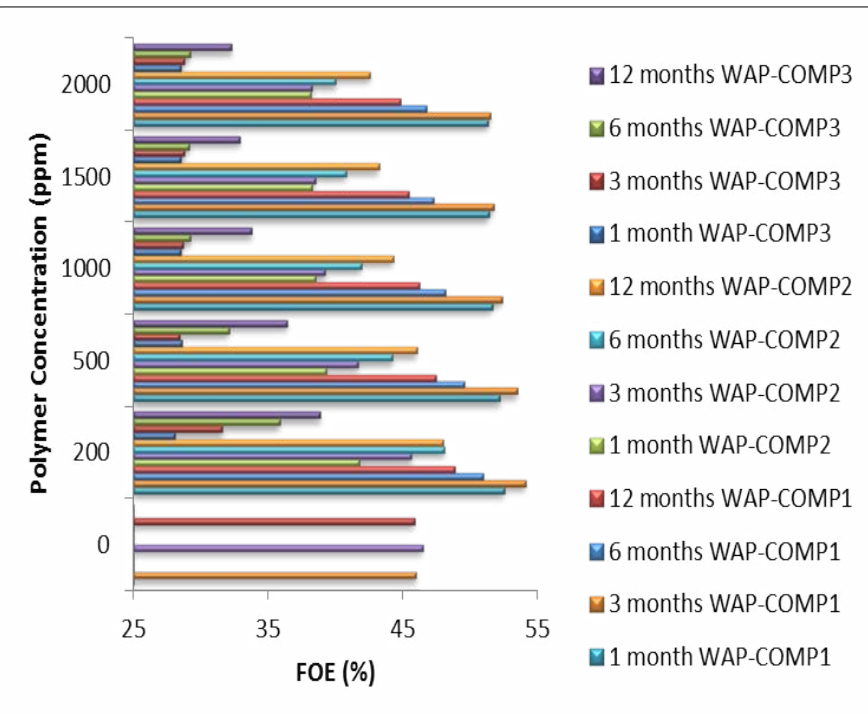

Figure 6. FOE of different scenarios of WAP injection.

Also, it has been observed that the injection rate was not maintained at the desired rate of 1500 STB/D and it has been reduced as the process of injection is going on; since it can't sustain the pressure in the reservoir. Moreover, maintaining constant injection rate of 1500 STB/D throughout the flood was attempted, leading to a sharp increase in pressure exceeding the fracture pressure of the formation.

In addition, injecting relatively larger slugs in the WAP process when COMP2 is applied increased the oil recovery by $1.63 \%$ and $1.49 \%$ when 0.014 and 0.0285 PV were injected respectively both at $200 \mathrm{ppm}$. Hence, the water cut has not reached the $90 \%$ limit at 2050; leading that the WAP process in this case can recover more oil where the project needs to be implemented for further time.

When COMP3 is attempted, the following results were observed:

- Delay in breakthrough compared to the other well completions applied.

- A further delay in breakthrough is noticed as the concentration of polymer solution increases from 200 ppm to $2000 \mathrm{ppm}$.

- Water cut was in the range of 10 to $15 \%$ when 2000 ppm is used.

- Reservoir pressure is maintained better when the WAP cycle time increases. 
Generally, the results reveal that COMP3 is not favorable to be implemented as a WAP process. Moreover, what has been recovered at 2050 by water injection is much more promising technically and economically.

Extending the project for another 50 years may lead to favorable results in terms of $\mathrm{FOE}$, since the water cut is still below $60 \%$ in the extreme case (200 ppm, 1 year WAP injection).

A comparison between the different options is presented in figure 6 in terms of oil recovery versus different polymer concentrations ranging between 200 to $2000 \mathrm{ppm}$ for all completions and WAP injection time intervals (different PV).

As shown, COMP1 gave the highest oil recovery ranging between $46.25 \%$ using 1000 ppm when 0.0285 PV is injected to $54.08 \%$ using $200 \mathrm{ppm}$ when $0.00704 \mathrm{PV}$ is injected. Moreover, the oil recovery increases with lower polymer concentration used.

Furthermore, the least recovery was obtained when each slug of water and polymer solution is injected for a year and the highest is when both slugs are injected for a period of one and three months, this is applied when COMP1 is used.

In general, as polymer concentration deceases as well as the WAP timing decreases, improvement in recovery is attained using COMP1. The opposite occurred using COMP2, where increasing the slug size is favorable in this case at low concentration of $200 \mathrm{ppm}$. Furthermore, COMP3 showed unfavorable results for all cases, and improvement in the sweep efficiency is not attained.

In here, it should be noted that since the WAP ratio is 1:1; this means that equivalent volumes of water and polymer are injected and the only difference in this case is the slug size of the injectant.

Therefore, implementation of WAP process at small time interval of one to three months $(0.00235,0.00704 \mathrm{PV})$ gave the highest oil recovery where COMP1 is used at relatively low polymer concentrations of $200 \mathrm{ppm}$.

Polymer slug injection: To implement polymer slug injection, forty-five simulation runs were simulated at different polymer concentrations, well completion, and polymer slug sizes.

The slug size in this case is $0.0685,0.0856$, and $0.143 \mathrm{PV}$ which corresponds to two, three, and five years of polymer injection. The polymer slug injection started after implementing water flooding for two years; then the run will proceed with water injection.

At the start of the flood, the reservoir pressure decreases and as soon as the injected solution started to breakthrough, the pressure raised a little bit. During the polymer injection period, the pressure is decreased and maintained. The following inferences can be drawn regarding the implementation of COMP1 using different concentrations and slug sizes:

- $1000 \mathrm{ppm}$ is the optimum polymer concentration where maximum recovery is achieved.

- Increasing the polymer slug size; does not necessarily mean an increase in oil recovery. This might work at low polymer concentrations; where for example an increment in FOE of $0.75 \%$ is attained when $200 \mathrm{ppm}$ is injected for five years compared to two years of polymer injection.

- Intermediate level of recovery is observed by applying polymer slug injection. An increment in oil recovery of $3.28 \%$ can be reached by injecting polymer solution of $1000 \mathrm{ppm}$ concentration over two years and this is the maximum that can be achieved when all layers were completed for injection and production.

- The fifteen options attempted were favorable and increase the oil recovery in the range of $1.47-3.28 \%$ over water flooding. The economics in this case will take the decision.

Completing the injector and producer as stated by COMP2 and applying the polymer injection for a period of two, three, and five years respectively; reveal the following findings:

- The maximum recovered oil at 2050 is $47.55 \%$, $47.50 \%$, and $47.34 \%$ when 500 ppm of polymer concentration is injected for two, three, and five years correspondingly. Hence, marginal differences were noticed.

- Comparable FOE was obtained using 200 ppm especially when the polymer is injected for three and five years.

- As the polymer concentration increased beyond 500 ppm, the FOE is reduced.

- Injecting polymer solution of 1500 ppm and 2000 ppm for five years showed a decrease in oil recovery by $0.47 \%$ and $1.02 \%$ respectively.

When the well is completed using COMP3; the maximum oil recovery of about $48 \%$ is obtained by the use of $500 \mathrm{ppm}$ when the polymer slug is injected for three years. Also, it has been observed that marginal differences encountered between $200 \mathrm{ppm}$ and $500 \mathrm{ppm}$ when the polymer in injected for the same period; where the selection of the best option will be based on the economic study. Injecting polymer for two and five years didn't recover extra oil over the water flooding process. Two years injection was not enough to sweep the oil and increment the recovery; hence comparable results with the water flooding option were obtained.

Furthermore, a reduction in oil recovery is observed when polymer slug injection for five years is implemented at the different concentrations during the project time period. This could be referred to the well completion used were both wells (injector and producer) are completed in geological layers one and three with relatively low permeability when compared to the middle one; causing a blockage of the pores when it has been interacted with the formation, leading to inefficient sweeping of the oil.

A comparison between the different options attempted as polymer slug injection is presented in figure 7 in terms of FOE versus different polymer concentrations ranging between 200 and $2000 \mathrm{ppm}$, for the three well completions investigated, and polymer injection period (different PV). 
The maximum oil recovery could be achieved by implementation of polymer slug injection after two years of water flooding for a period of two years using COMP1, and by injecting $1000 \mathrm{ppm}$ of the polymer solution. Furthermore, injecting the polymer solution at high concentrations of 1500 ppm and $2000 \mathrm{ppm}$ is not beneficial as well as completing the well as in COMP3, where both the injector and producer are completed in geological layers one and three.

Generally, COMP3 is not recommended to be used as an option to maximize the oil recovery by polymer flooding.

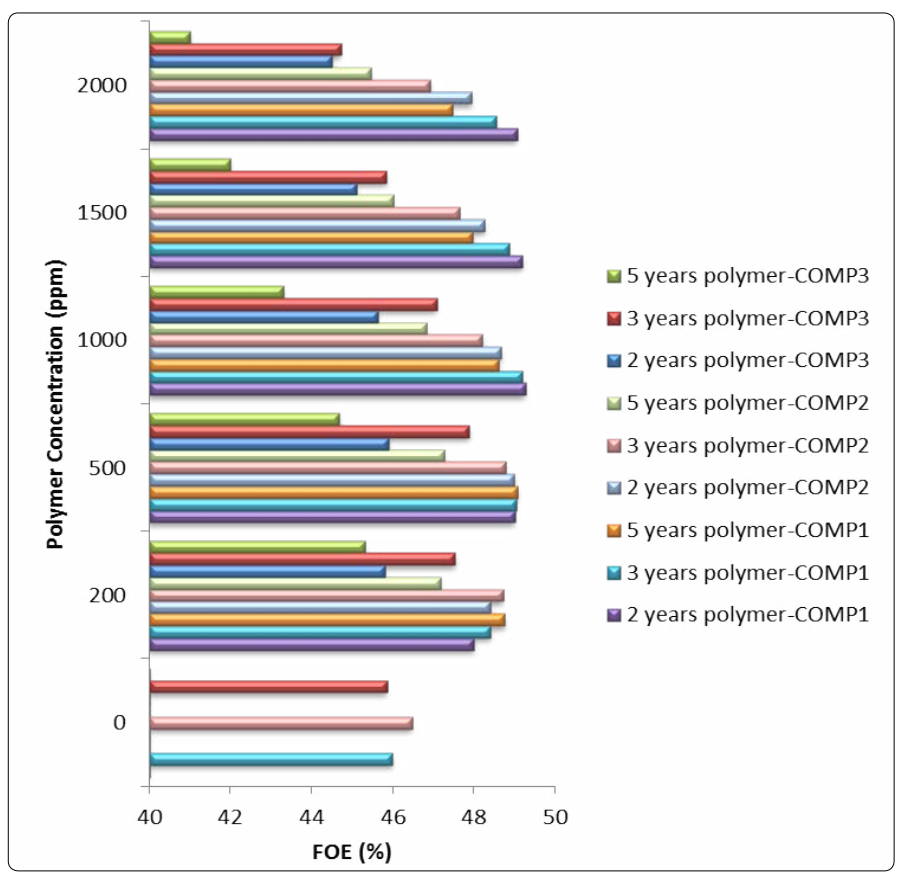

Figure 7. FOE at different scenarios of polymer slug injection.

In general, the required volumes of polymer solution to be injected using the slug injection process is less than the other two options including continuous polymer injection and WAP injection. Also, through the polymer slug injection sensitivity analysis; the water cut approaches its economic limit of $90 \%$ in 2050 . Therefore, when the polymer is injected in a continuous basis or as equally alternating slug with water; the economic limit of water cut is still not reached. This lead that extending the study period for more than 41 years could improve the oil recovery; keeping in mind that any decision is based on the management and business plan of the project.

\section{Conclusion}

The results of this study lead to the following conclusions:

- Implementation of polymer flooding by different processes including continuous polymer injection, WAP injection, and polymer slug injection proves that the sweep efficiency has been improved.

- The effect of polymer concentration on the continuous polymer injection process is not clear. Thus, it is more economical to use $200 \mathrm{ppm}$ that gives the highest FOE.

- Continuous polymer flooding is not practical since it requires large volumes of polymer to be injected.

- A maximum oil recovery of $54 \%$ could be achieved by the employment of WAP injection using minimum polymer concentration of $200 \mathrm{ppm}$, WAP cycle of three months and using COMP1.

- A maximum oil recovery of $49.26 \%$ could be achieved by polymer slug injection for two years at $1000 \mathrm{ppm}$ using COMP1.

- Polymer slug timing is an effective technical parameter to be studied and it is a function of formation properties. Three years of polymer slug injection gave the maximum oil recovery.

- Generally, the oil recovery has been affected by polymer concentration when other technical parameters are held constant. Decreasing the polymer concentration, increases the oil recovery in the synthetic model used.

- Polymer flooding promotes incremental oil production by increasing the amount of oil produced before reaching the economic water cut limit of $90 \%$.

- The effect of polymer flooding options attempted will be more favorable when it is applied on heavy oils.

\section{References}

1. Khan G. Experimental studies of Carbon dioxide Injection for Enhanced Oil Recovery Technique. Aalborg University Esbjerg. 2000.

2. Romero-Zerón L. Advances in Enhanced Oil Recovery Processes. In: Introduction to Enhanced Oil Recovery (EOR) Processes and Bioremediation of Oil-Contaminated Sites. 2012. doi: 10.5772/45947

3. Abadli F. Simulation Study of Enhanced Oil Recovery by ASP (Alkaline, Surfactant and Polymer) Flooding for Norne Field C-segment. Norwegian University of Science and Technology. 2012.

4. Huseynli P. Evaluation of Polymer Flooding for Enhanced Oil Recovery in the Norne Field E-Segment. Department of Petroleum Engineering and Applied Geophysics; 2013.

5. Abdul-fattah Abed A, Zekri AY. Optimum Non Hydrocarbon Gas Injection Development Process and Ultimate Recovery Maximaization. Abu Dhabi, (AD): Society of Petroleum Engineers; 2008. 